\title{
Of Politicians and Technocrats, and Why Global Health Scholars Are Inevitably a Bit of Both: A Response to Recent Commentaries
}

\author{
Gorik Ooms*
}

\author{
*Correspondence to: Gorik Ooms, Email: gorik.ooms@uni-heidelberg.de \\ Copyright: (๑) 2016 by Kerman University of Medical Sciences \\ Citation: Ooms G. Of politicians and technocrats, and why global health scholars are \\ inevitably a bit of both: a response to recent commentaries. Int J Health Policy Manag. \\ 2016;5(7):449-450. doi:10.15171/ijhpm.2016.56 \\ Received: 21 April 2016, Accepted: 7 May 2016, ePublished: 11 May 2016
}

$\mathrm{W}$ hen I wrote "Navigating Between Stealth Advocacy and Unconscious Dogmatism: The Challenge of Researching the Norms, Politics and Power of Global Health," my primary intention was to fuel the interdisciplinary dialogue on norms, politics, and power that had been started in this journal by others. Considering the five insightful comments, ${ }^{2-6}$ responding to my article, I think I can claim at least that: the dialogue continues, as it should.

As I borrowed the title for this response from Ilona Kickbusch's comment, let me start there. I fully agree with Kickbusch when she writes that "[p]olitics play a central part in determining health and development outcomes, health is to a large extent a political choice."4 And I would argue that it is even more true for global health. At the national level, there are nascent examples of a division of labour between 'politics' and 'technocrats.' The best, or best-known, example of which is the National Institute for Health and Care Excellence (NICE) in the United Kingdom. NICE's staff and scholars quite often claim that they make recommendations (to the National Health Service [NHS], about the adoption of new healthcare technology), on the basis of empirical evidence only. That may be true, but NICE operates within a political framework, circumscribed by politicians. In short: politicians decide, first, that all additional life years are of equal worth, and, second, how big or small the budget of the NHS is; then the NICE technocrats can calculate how the given budget can produce maximum results.

Is this the ideal division of labour between politicians and technocrats? Perhaps it is. But even in the United Kingdom, it does not always work. When NICE consistently recommended against the adoption of new cancer drugs, of which the added value (in comparison with other options) was questionable, the United Kingdom decided to create a Cancer Drug Fund, setting aside a particular budget for the treatment of people with cancer. Politicians thus overruled the technocrats. Given that the Cancer Drug Fund is being 'taken over' by NICE, it may be the exception that confirms the general rule. ${ }^{7}$ Or it may indicate that when 'the people' perceive that a case is deeply unjust - namely, the availability of new cancer drugs being restricted to the wealthier part of the population only - no amount of technocratic argument will change their minds, and politicians are 'obliged' to interfere.

More importantly, the existence of NICE, and how it functions, illustrates how politics and technocracy are deeply entangled at the international or global level. At the global level, there is no institution in a position to play the technocratic role of NICE. And even if we had one - arguably, the World Health Organization (WHO) could assume this role - at the global level, we do not have the equivalent of the UK Parliament, that sets the political framework for NICE. It would be nice pun intended - if we could have an international agreement on a US $\$ 86$ per person per year healthcare financing floor, for which national governments and the international community would assume shared responsibility for financing, ${ }^{8}$ and then have the WHO make recommendations on how to allocate it. But until we have such an agreement, the suggestion of adopting it is inevitably a political act (and so is any global health recommendation that is based on assumptions of available resources). To be clear: I do not think that politics in global health are bad, and I am very aware of my own political role (and its limitations) as a global health scholar: I think politics are inevitable, but prefer open and transparent politics over stealth politics; I prefer conscious politics over unconscious politics.

This being written, I do believe that there is an important distinction between, on the one hand, being political and acting upon internationally agreed norms, and on the other hand, being political and acting upon one's own normative beliefs. For example, the two essential international human rights treaties - namely the International Covenant on Civil and Political Rights and the International Covenant on Economic, Social and Cultural Rights - are far too statecentred for my personal cosmopolitan taste. If human rights are rights one has because of being part of humanity, their realisation should not be as dependent on the national resources of the state in which one resides. For my personal taste, the $\$ 86$ per person per year healthcare financing floor is not good enough - it should be higher. But while I am comfortable saying, as a lawyer, that the US $\$ 86$ per person per year healthcare financing floor is grounded in international human rights law, I find it more difficult to argue that international human rights law demands a floor of about $\$ 500$ per person per year. From a global health perspective, spending at least $\$ 500$ per person per year on healthcare in all countries would be far more efficient than spending $\$ 86$ in some countries and $\$ 8600$ in some other countries. And 
from a cosmopolitan perspective, all human life years have equal value, so spending at least $\$ 500$ per person per year on healthcare in all countries would have my vote. But a $\$ 86$ per person per year healthcare financing floor would be progress, and it is grounded in international human rights law, so I limit my 'claim' to that.

Which brings me to the comments by Clemet Askheim, Kristin Heggen, and Eivind Engebretsen, ${ }^{2}$ and by Lisa Forman. ${ }^{3}$ Although formulated in very different ways, the critiques of Askheim et al and of Forman point at a similar issue. Is it not naïve to think that a rational (scholarly) analysis of international human rights law will bring about a rational consensus and thus progress, without political conflicts? ${ }^{2}$ Would such a scholarly analysis not obscure the unseen norms and powers of global health; would it not obscure the "primary mechanism by which power sustains and reinforces itself" ? ${ }^{3}$ In my defense: I never wrote that a scholarly analysis of international human rights law, and its integration in global health scholarship, would somehow 'solve the problem' in itself. But I may have implied it. So, to be clear: I have no hopes whatsoever that a scholarly analysis of international human rights law will suddenly convince the political leaders of all 200 or so members of the United Nations that a $\$ 86$ per person per year healthcare financing floor, with shared national and international responsibility, should be included in the Sustainable Development Goals or any other declaration of that kind. My only hope is that the $\$ 86$ figure will highlight the truly scandalous nature of all the human deaths and suffering that could be avoided, if only states acted upon the commitments they made in international human rights treaties. And, by highlighting the truly scandalous nature of all the human deaths and suffering that could be avoided if only states acted upon their promises, I hope it can fuel political struggle and unveil the "primary mechanism by which power sustains and reinforces itself" 3 and that makes us - global health scholars - look for solutions that fit into $\$ 10$ budgets, solutions which we know are excluding people (like user fees) and suboptimal (like focusing on prevention when prevention and treatment are the only appropriate solution). That brings me to Robert Marten's comment. He is right: the common definition(s) of global health, or lack thereof, yield power. As I highlighted in my original essay, some definitions of global health are explicitly normative, and contain at least elements of global health justice, like "achieving equity in health for all people worldwide," or "promoting health for all." 10 I have argued elsewhere that these definitions contain a certain degree of wishful thinking, and that a more descriptive definition of global health would probably focus more on the enlightened self-interest element in international cooperation for health. ${ }^{11}$ Nevertheless, at the risk of confusing our audiences, I would prefer to stick to or adopt the more normative definition, if only to keep ourselves aware of what global health could be and should be about - as long as we do not make ourselves believe that the reality of global health is equitable in any way.

Last but not least, Johanna Hanefeld's comment points out the importance of global governance, for and of health, as a field for research and study. ${ }^{6}$ I can only agree. If we can accept that, as global health scholars, we are inevitably politicians and technocrats at the same time, it should be self-evident that we need a better understanding of the political arena we are part of - and that will indeed require "substantial resources and investment."' But first and foremost, it will require an interdisciplinary dialogue, including the social sciences and humanities.

Ethical issues

Not applicable.

Competing interests

Author declares that he has no competing interests.

Author's contribution

$\mathrm{GO}$ is the single author of the paper.

\section{References}

1. Ooms G. Navigating between stealth advocacy and unconscious dogmatism: the challenge of researching the norms, politics and power of global health. Int $J$ Health Policy Manag. 2015;4(10):641-644. doi:10.15171/ijhpm.2015.116

2. Askheim C, Heggen K, Engebretsen E. Politics and power in global health: the constituting role of conflicts: Comment on "Navigating between stealth advocacy and unconscious dogmatism: the challenge of researching the norms, politics and power of global health." Int J Health Policy Manag. 2016;5(2):117119. doi:10.15171/ijhpm.2015.188

3. Forman L. The ghost is the machine: how can we visibilize the unseen norms and power of global health? Comment on "Navigating between stealth advocacy and unconscious dogmatism: the challenge of researching the norms, politics and power of global health." Int J Health Policy Manag. 2016;5(3):197199. doi:10.15171/ijhpm.2015.206

4. Kickbusch I. Politics or technocracy - what next for global health? Comment on "Navigating between stealth advocacy and unconscious dogmatism: the challenge of researching the norms, politics and power of global health." Int $J$ Health Policy Manag. 2016;5(3):201-204. doi:10.15171/ijhpm.2015.209

5. Marten R. Global health warning: definitions wield power: Comment on "Navigating between stealth advocacy and unconscious dogmatism: the challenge of researching the norms, politics and power of global health." Int $\mathrm{J}$ Health Policy Manag. 2016;5(3):207-209. doi:10.15171/ijhpm.2015.213

6. Hanefeld J. Advancing global health - the need for (better) social science: Comment on: "Navigating between stealth advocacy and unconscious dogmatism: the challenge of researching the norms, politics and power of global health." Int $\mathrm{J}$ Health Policy Manag. 2016;5(4):279-281. doi:10.15171/ijhpm.2015.213

7. Timmins N. At last, NICE to take over the Cancer Drugs Fund. BMJ. 2016;352:i1324. doi:10.1136/bmj.i1324

8. Røttingen JA, Ottersen T, Ablo A, et al. Shared Responsibilities for Health: A Coherent Global Framework for Health Financing. Final Report of the Centre on Global Health Security Working Group on Health Financing. https://www.chathamhouse.org/ sites/files/chathamhouse/field/field_document/20140521Health Financing.pdf

9. Koplan JP, Bond TC, Merson MH, et al. Towards a common definition of global health. Lancet. 2009;373(9679):1993-1995. doi:10.1016/s0140-6736(09)60332-9

10. Beaglehole R, Bonita R. What is Global Health? Global Health Action. 2010;3:5142.

11. Ooms G, Rachel H, Decoster K, Van Damme W. Global health: what it has been so far, what it should be, and what it could become. Working paper/syllabus. http://www.itg.be/itg/ Uploads/Volksgezondheid/wpshsop/SHSOP\%20WP\%202\%20 Ooms\%20Global\%20Health.pdf 